\title{
Developing a scale for proactive improvement within logistics outsourcing relationships
}

\section{Scale for proactive improvement}

Carl Marcus Wallenburg

Technische Universität Berlin, Berlin, Germany

A. Michael Knemeyer

Fisher College of Business, The Ohio State University, Columbus, Ohio, USA

Thomas J. Goldsby

Gatton College of Business and Economics, University of Kentucky, Lexington, Kentucky, USA, and

David L. Cahill

Fisher College of Business, The Ohio State University, Columbus, Ohio, USA

\begin{abstract}
Purpose - The purpose of this paper is to establish a scale for the measurement of proactive improvement, in general, and then more specifically in terms of cost- and service-focused improvement in logistics outsourcing arrangements.

Design/methodology/approach - Upon completing a review of the literature, scale development is completed in five phases. The first two phases focus on item generation and qualitative validation. The third phase (quantitative pilot testing) involves a sample of 220 logistics managers in Germany. The fourth phase replicates these findings with a sample of 250 US logistics managers. The final phase differentiates the general scale tested and replicated in the previous two phases by assessing the merit of cost- and service-focused scales adapted from the general scale among a separate sample of 298 logistics managers in Germany.
\end{abstract}

Findings - After eliminating one measurement item, the German and US samples provide support for a four-item scale to measure general proactive improvement. Subsequent analysis with a separate sample finds strong support for scales that are adapted to capture the distinct aspects of cost- and service-focused improvement.

Research limitations/implications - Research indicates that one of the key differentiators in the success of logistics outsourcing relationships is the service provider's ability to achieve proactive improvement, or customer-oriented ex post adaptations that benefit the customer after the relationship's formation. Little empirical research has been conducted to assess the influence and merit of such improvements. The establishment of valid scales is an important initial step towards understanding the value and nature of proactive improvement in logistics outsourcing relationships. Practical implications - Future research using the established scales should help provide practitioners with a better understanding of the value and nature of proactive improvement in logistics outsourcing relationships.

Originality/value - The paper employs a thorough multi-phase/multi-sample approach across two distinct countries to devise a scale for an important construct in logistics outsourcing research.

Keywords Outsourcing, Channel relationships, Cost reduction, Service improvements, Germany, United States of America

Paper type Research paper

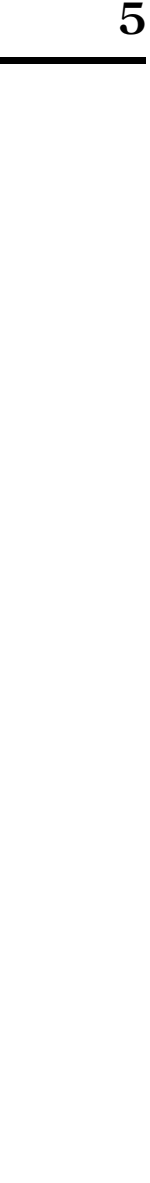

\section{Introduction}

As more companies have focused on their core competencies, the degree and scope of The International Journal of Logistics logistics outsourcing has increased significantly over time. Users of logistics

The ordering of authors is not indicative of individual contribution, but is in reversed alphabetical order.

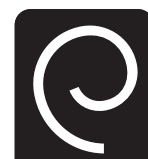

Emerald

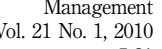
pp. $5-21$

Emerald Group Publishing Limited 0957-4093 DOI 10.1108/09574091011042151 
IJLM

21,1

6 outsourcing consistently report cost reductions in the range of 12-15 per cent, fixed logistics asset reductions in excess of 20 per cent, and order cycle reductions of 20-30 per cent (Langley, 2008). Today, the total percentage of current logistics expenditures directed to outsourcing is 49 per cent in North America, 61 per cent in Europe, 57 per cent in Asia Pacific, and 48 per cent in Latin America, with predictions that these percentages will continue to grow in all regions over the next few years (Langley, 2008). Thus, logistics outsourcing continues to be an area of great importance for companies to better understand.

As the specificity of service has increased so has the relational nature of outsourcing arrangements. Consistent with Transaction Cost Economics (TCE) (see Williamson, 1985), outsourcing has taken on a rather "long-term" relational nature rather than the notion of spot-market transactions that was the more dominant perspective in the past (Murphy and Wood, 2004). Especially in dynamic markets, such a cooperative approach does not only involve stronger interaction (plus higher dependency due to specificity and longer contracts), but also the risk of maladaption and the costs associated with it (Rindfleisch and Heide, 1997). TCE refers to this domain as the $e x$ post adaptation problem (Rindfleisch and Heide, 1997).

To date, research on value in business-to-business relationships (such as logistics service provider (LSP) - user relationships) has primarily focused on the importance of meeting customer-initiated requests for change (Beverland and Lockshin, 2003; Flint et al., 2002; Ulaga and Eggert, 2006). Merely responding to user requests may not result in relationship continuance, particularly given that 42 per cent of users indicate a lack of continuous, ongoing improvements and achievements in offerings as a pervasive problem of LSPs (Langley, 2008).

In the field of business services, both literature (see, e.g. Beverland et al., 2007) and anecdotal evidence suggest that in a situation of necessary change, being proactive is potentially a very effective strategy for service providers seeking to satisfy customers and increase loyalty. In contrast, in the field of logistics, service providers have traditionally taken a rather reactive approach to meeting potentially changing customer needs. Still today most LSPs tend to change the service (solution) delivered to a customer primarily as a reaction to requests made by this customer and not proactively initiated by themselves (this was confirmed by focus group discussions with representatives from large international LSPs, including Ceva, DB Schenker, DHL Logistics, Hellmann Worldwide Logistics, Kuehne + Nagel, Logwin, Panalpina, Rhenus, and UPS, as well as interviews with representatives from medium-sized local and regional LSPs). Historically, this may not have been an issue of importance for the customers. Many companies maintained a degree of logistics knowledge in-house that enabled them to design logistics solutions and identify necessary and useful changes by themselves, while outsourcing the responsibility for execution to their LSPs.

Today, however, as the logistics services provided have grown in complexity and customers have increasingly focused their managerial resources on other areas of business, the competencies of LSPs no longer lie in execution alone but also in solution design. Thus, in today's environment customers often will not be able to identify and request the optimal solution design on their own.

This dependence viewpoint is reflected by customers expecting their LSPs to continuously drive service innovation (Flint $e t$ al., 2005) and develop ideas about improvements and to give them insights about new technologies or concepts that evolve (Engelbrecht, 2004). Consequently, logistics outsourcing relationships increasingly involve customers willing to depend on the competencies of the LSP to 
enhance their competitive positioning (Bhatnagar and Viswanathan, 2000). For the customer of an LSP, this includes using the innovative capabilities of the LSP not only to create and implement an adequate logistics solution but also to strive for continuous improvements in order to further enhance it. In terms of TCE, this means that ex post adaptations within logistics outsourcing relationships that solely rely on customer requests will result in a lower performance than those that utilize both customer requests and the proactive initiative of the respective LSP.

To foster research on this aspect of outsourcing relationships, the objective of this paper is to establish a general scale for the measurement of proactive improvement, which refers to the actions taken by an LSP in a specific relationship. In order to ensure applicability of the scale, we aim at both being able to measure proactive improvement on the superordinate level, but also with respect to certain aspects of adaptation (e.g. reducing costs and improving the service level). We should emphasize that the current study is intended to be an initial step towards the goal of developing a scale to effectively measure the latent construct of proactive improvement. Although an examination of proactive improvement can take many forms, the current study strives to provide researchers a tool to better control for this aspect of logistics outsourcing relationships in their studies and serve as a basis for the development of scales focused on specific areas of proactive improvement.

The next section establishes the conceptual setting by outlining the role of proactive improvement in outsourcing relationships and potential effects of this variable. The third section is devoted to the development and testing of the actual measurement scale. This section includes an adaptation of the general scale to reflect the unique aspects of cost and service-focused improvements. The paper closes with a short discussion about implications of the current study and future research avenues utilizing the construct and its measurement scale.

\section{Framework}

2.1 The role of proactive improvement in logistics outsourcing relationships

Proactive improvements - or ex post adaptations, as they would be termed in TCE made by an LSP within an outsourcing relationship are an act of innovation as they are "an idea, practice, or object that is perceived as new by an individual or other unit of adoption" (Rogers, 1995). These innovations improve the competitiveness of an LSP and may be utilized for services rendered in the form of market exchange, where autonomous adaptation occurs (Williamson, 2008), as well as for services provided in relationships in the form of cooperative adaptation. On the other hand, an innovation may be relationship-specific and address only a single customer. This class of innovation obviously is irrelevant for standardized services as these are exchanged on spot-markets and occur as transactions between "faceless" economic actors (Williamson, 2005).

When the outsourcing relationship is established, the so-called fundamental transformation occurs and induces the problem of maladaption (Williamson, 1985). During an ongoing relationship, the LSP is subject to only a limited amount of competition since the customer's switching opportunities are reduced due to the contractual agreements (Williamson, 1985). Additionally, often the obligation for the LSP to innovate cannot be specified appropriately ex ante, as it is unclear what types of innovation may be beneficial in the future and which advancements will be available for them. As a result, innovations made by an LSP within a relationship are most often voluntary.

Innovations within ongoing relationships can be termed improvements as they are made to existing services. They can be classified into two groups:

\section{Scale for proactive improvement}


IJLM

21,1

8

(1) reactive improvements by an LSP generated as a result of customer requests; and

(2) proactive improvements based upon an LSP's own initiative.

Proactive improvement refers to an individual LSP, which given that a potential innovation is beneficial to its customer - proactively enhances the service provided to this specific customer. Although it might be argued that the proactive implementation of pre-existing services is not an innovative act, the current study defines an innovation as being the situation where "an idea, practice or object that is introduced to a relationship is perceived as new by an individual or other unit of adoption" (Rogers, 1995). Thus, in the current study, if the service is new to the customer it is viewed as being innovative.

The potential for adaptation within logistics outsourcing relationships results from various factors. For one, the bounded rationality of the parties restricts their ability to ex ante design the service in a way that accounts for all possible dependencies (Williamson, 1991, 1993). Second, over time, additional technologies may become available that enable service improvements. Third, uncertainty about the future exists regarding the strategies and products of the customer on the one hand and the needs and requirements of the customer's customers on the other hand. Fourth, over time the LSP gains experience regarding the provision of the service and the needs of the customer. Combined, these factors can cause the services initially provided by the LSP to deteriorate in efficiency and effectiveness over time.

\subsection{Potential effects of proactive improvement}

Customer-oriented proactive improvements yield functional value to the customer as costs incurred to the customer are reduced or the benefits received increased. Thus, efficiency and/or effectiveness are enhanced. Deepen et al. (2008) demonstrate the positive effects of proactive improvements for logistics outsourcing relationships. Yet, in outsourcing relationships it is not possible to contractually specify all details of the transaction ex ante. Uncertainty about the LSP's future behavior remains. The customer does not know whether the LSP will act in the customer's best interest (which would mean adapting the service offering, whenever beneficial to the customer) or rather behave opportunistically when given the chance. Here, proactive improvements initiated by the LSP come into play. Proactiveness shows commitment by the LSP and utilizes the LSP's specific competencies, which go beyond the competencies of the customer. As proactive improvement usually yields a major part of its benefits for the LSP - i.e. a more stable relationship - only at a later stage, it is a costly signal any LSP with opportunistic intentions would hesitate to send (Kydd, 2000). This reduces the uncertainty of the customer and adds to his relationship value by reducing risks and increasing the trustworthiness of the LSP. Thus, proactive improvement yields both functional value and relationship value for the customer.

From the LSPs perspective, the higher customer satisfaction and loyalty that is obtained through proactive improvements should offer motivation for pursuing these behaviors. Building upon social exchange theory (SET) (Thibaut and Kelley, 1959), a customer should achieve higher benefits (in the form of better performance) from an LSP that displays proactive improvement, and this increased value (both relational and functional) received by the customer will raise the likelihood that the customer maintains and expands the existing relationship (Lambe et al., 2001). This could lead to a comparative advantage for the LSP, when the customer compares the achieved benefits to an alternative to the LSP. In addition, proactive improvement behaviors 
create a positive signaling effect. When an LSP conveys that it proactively improves logistics systems, this will create confidence within the customer. As a result, commitment and trust are nurtured, relational governance norms are established, and customers might be willing to forego present benefits for anticipated future benefits, when the LSP displays proactive improvement behaviors. In addition, Lemon et al. (2002, pp. 12-13) point out that customers are generally forward looking, such that the positive signaling effect in itself should foster a customer's propensity to continue, and perhaps expand, a relationship with an LSP. Wallenburg's (2009) study supports this perspective by relating proactive improvement to three distinct dimensions of loyalty.

\section{Scale development}

\subsection{Literature review/idea for the scale}

The initial idea for this scale to measure proactive improvement originated with Engelbrecht (2004), who noticed in his research that users of logistics services articulated a desire for their LSPs to provide innovation and optimization within their outsourcing arrangements. A review of scale handbooks and overviews of existing scales (see Keller et al., 2002) failed to identify a scale that specifically measures proactive improvement within logistics outsourcing relationships. Thus, based on this notion and the necessity of ex post adaptation in logistics outsourcing relationships as portrayed by TCE, the need for a corresponding scale to measure proactive improvement was established and a process was determined to develop a measurement scale. After establishing the desire for a scale to measure proactive improvement, we started our scale development effort with the previously mentioned definition of proactive improvement, which refers to an individual LSP, which given that the change is beneficial to its customer - proactively enhances the service provided to this specific customer. In this sense, proactive improvement always is relationship-specific. From this starting point, the development of the scale progressed through four distinct phases.

3.1.1 Phase one - item generation. In the first phase, exploratory interviews were conducted on the broader topic of logistics outsourcing - focusing on different aspects of logistics outsourcing and its underlying relationships. As part of these interviews, specific attention was paid to the aspect of reactive and proactive adaptation/ improvements made by LSPs in outsourcing arrangements and potential measurement of proactive improvement. These interviews were conducted (in Germany) with a total 13 managers, eight of them representing users and five of them representing providers of logistics services in order to ensure congruence of views across both sides of the logistics outsourcing relationship.

These interviews served to provide a better understanding of the different facets of adaptation within logistics outsourcing relationships. It was established during the interviews that the key elements related to this construct were to capture the aspect of proactiveness demonstrated by the LSP in combination with the relationship-specific innovation provided by the LSP. It also became clear that the measurement would best be accomplished by examining the customer perceptions of the proactive improvement activities of the LSP. The interviews suggested that the success of the relationship it is not directly related to what the LSP tries to do in the relationship, but is dependent on what customers actually notices.

Starting with initial ideas on the potential measurement scale for proactive improvement, this first phase also served to establish a common understanding on how measurement of the defined variable could be accomplished. As a result of an iterative process, a scale of five items that reflect the degree of proactive improvement of an LSP

\section{Scale for proactive improvement}


IJLM

21,1

\section{0}

in a customer-specific relationship was established. Through interactive discussions with the interviewees and the feedback they provided related to the measurement items this scale was then further refined. The resulting measurement items that reflect the level of proactive improvements (measured on a seven-point Likert-type scale anchored by strongly disagree and strongly agree) are:

(1) The LSP puts strong effort into continuously optimizing logistics processes.

(2) The LSP continuously makes suggestions for improvements of activities, even those outside its direct responsibility.

(3) When the situation changes, the LSP by itself modifies the logistics activities and processes, if this is useful and necessary.

(4) The LSP shows initiative by approaching us with suggestions for improvement.

(5) The LSP shows a high level of innovation.

All above items are of a reflective nature and will result in higher scores on the Likert scale for an LSP that shows high levels of proactive improvements. Whereas all of the proposed items operate at a similar level of abstraction, Item 5 is the most global of the five indicators, referring to innovativeness of the LSP in this relationship. Item 1 is also rather general and refers to the customer's perceptions on LSP's efforts of continuously improving processes in this relationship. The remaining items use more specific areas of the relationship to reflect the level of proactive improvements by the LSP. Item 2 refers to improvement efforts outside the LSP's direct responsibility, which is indicative of the LSP's motivation to increase the customer's performance. Items 3 and 4 include self-motivational aspects, i.e. they refer to the degree to which an LSP strives to improve its customer's logistics processes, without direct motivation by the customer.

3.1.2 Phase two - qualitative validation. The second phase of the scale development process served as a first validation of the developed scale from the initial phase. The newly developed scale was pretested/discussed in both the USA and Germany with ten managers from outsourcing companies and LSPs and 12 logistics researchers to assess its applicability for measuring the intended construct. On the basis of the feedback received during these interviews, no changes and/or refinements were required, which indicates a certain "stability" of the measurement scale.

3.1.3 Phase three - quantitative pilot test validation. In the third phase of scale development, a web-based survey was developed and implemented as part of a larger study on logistics outsourcing that also collected specific data to test the proactive improvement scale. As a "modern" version of traditional hardcopy surveys, web-based surveys carry the same advantages while at the same time negating many disadvantages associated with traditional mail-based surveys (Griffis et al., 2003).

The sample used in this phase consisted of 678 potential respondents from German companies. It was drawn from the company database of a leading European business school and offers a good representation of the basic population of logistics executives in manufacturing and trading industries in Germany. All potential participants received a pre-notification e-mail outlining the goals of the study (Mehta and Sivadas, 1995) and a few days later a link to the survey, which was in the German language. Survey recipients were asked to refer to their most important LSP relationship, thus ensuring the necessary strategic relevance of the issue to the respondents and to the business unit. The subsequent procedure followed the recommendations of Larson and Poist (2004) using incentives and two friendly reminder e-mails to increase the response rate. 
Discarding partially completed surveys, a total of 220 logistics managers participated in the study resulting in a usable response rate of 32.4 per cent, which can be regarded as very good. The sample demographics are displayed in Table I and show that medium and large companies are slightly overrepresented in the sample, perhaps indicative of their stronger reliance on logistics outsourcing. The data also shows broad representation of manufacturing and trading industries.

In addition to our filtering activities, two additional steps were taken to ensure that respondents were knowledgeable and appropriate sources of information. First, the survey was directed only to persons directly associated with logistics and/or supply chain management (SCM) activities within the firm thereby increasing the likelihood they would have familiarity with the outsourcing of logistics activities in their business unit. Additionally, the competency of the respondent was assessed on the basis of the respondent's personal information, per Kumar et al. (1993). In the sample, 82.2 per cent of respondents hold management positions in logistics, have been in their position for an average of 5.6 years, and have worked for the same company for 10.8 years. Hence, the sample's respondents were qualified for completing the questionnaire so that the samples can be assumed relatively free of informant bias. Non-response bias was assessed on the basis of Armstrong and Overton (1977) by comparing the answers to each of the items across early respondents and late respondents and no indication of response bias was found when applying an alpha level of 0.05 .

On the basis of this sample the reliability of initial scale was first assessed based on Cronbach alpha. Its value of 0.92 can be regarded as very good. We further applied an exploratory factor analysis (EFA) using the oblimin-rotation - here and in all subsequent applications of the EFA. The EFA showed that all five items load on one factor, which explains 79.72 per cent of total variance.

Then further assessment was conducted via a confirmatory factor analysis (CFA) using AMOS 17.0 - here and in all subsequent applications of CFA. The CFA $\left(\chi^{2}=25.354 \quad(\mathrm{df}=5 ; \quad p<0.001)\right.$; normed $\chi^{2}=5.073$, Comparative Fit Index $\mathrm{CFI}=0.975$, Tucker Lewis Index TLI $=0.949$; Root Mean Square Error of

Industry

Percentage

Automotive

12.7

Chemicals and plastics

Consumer goods

Electronics and related instruments

20.0

Food and beverage

8.2

Healthcare

Industrial equipment

Retailing

Others

Annual revenue (in millions of euros)

$<100$

$100-249$

250-499

500-999

$\geq 1,000$

No response

Note: $n=220$

\section{Scale for proactive improvement}

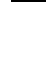


IJLM

21,1

Approximation RMSEA $=0.136$ ) indicate a non-sufficient fit. The non-standardized parameter estimates are provided in Table II.

To improve the fit of the measurement scale, indicator 1 was eliminated. This decision was made based on two pieces of information:

(1) indicator 1 has the lowest individual item reliability at 0.56 (all others are at 0.63 or higher); and

12

(2) the error term of indicator 1 is highly correlated with the error term of indicator 4 and of indicator 5 .

As displayed in Table III, after eliminating indicator 1 the remaining measurement scale with indicators 2-5 show good fit (Cronbach $\alpha=0.92, \chi^{2}=3.803$ (df = 2 ; $p=0.149$ ); normed $\chi^{2}=1.902$, CFI $=0.997$, TLI $=0.991$; $\mathrm{RMSEA}=0.064$ ).

3.1.4 Phase four - quantitative replication. The final phase involved replication and validation of the pilot test results obtained in the third phase. This replication and validation was conducted in a different research setting. Namely, data relating to the scale were collected and analyzed from a sample of users of LSP services in the USA.

In this phase, data were gathered from logistics professionals who were members of the Council of Supply Chain Management Professionals (CSCMP). The sample consisted of CSCMP members employed by manufacturers, distributors, and retailers in the USA who indicated experience with logistics outsourcing. As was the case in the third phase, a web-based survey method was used in a manner consistent with guidelines set forth by Griffis et al. (2003). Sample members were contacted via e-mail

\begin{tabular}{lccc}
\hline Proactive improvement & Estimate & $t$-value & $p$-value \\
\hline Item_1 & 0.812 & 12.099 & $<0.001$ \\
Item_3 & 1.000 & & $<0.001$ \\
Item_3 & 1.124 & 14.667 & $<0.001$ \\
Item_4 & 1.197 & 15.461 & $<0.001$ \\
Item_5 & 1.118 & 14.334 &
\end{tabular}

Table II.

Non-standardized parameter estimates

Item $\quad$ Proactive improvement

The LSP puts strong effort into continuously optimizing logistics processes

The LSP continuously makes suggestions for improvements of activities, even those outside its direct responsibility

When the situation changes, the LSP by itself modifies the logistics activities and processes, if this is useful and necessary

The LSP shows initiative by approaching us with suggestions for improvement

The LSP shows a high level of innovation

1.58

0.86

Table III.

Measurement scale results for the pilot test (Germany)

Notes: Cronbach $\alpha=0.92, \operatorname{AVE}=0.73$, composite reliability $=0.92 ; n=220$ 
and asked to complete the on-line survey instrument. Again, the recommendations of Larson and Poist (2004) were followed and incentives and friendly reminder e-mails were used to increase response rate.

E-mails were distributed to 1,448 potential respondents. Of those, 250 questionnaires were completed, corresponding to a usable response rate of 17.3 per cent. An analysis of the demographics suggests that the sample is well balanced with regard to industry affiliation, whereas large companies with yearly revenues of US\$1 billion or more are slightly over-represented (see Table IV). As suggested by Kumar et al. (1993), respondent competency was assessed on the basis of personal information provided by the respondents. Informant bias does not seem to be an issue in the current study based on respondents indicating:

- that 97 per cent of them were at the logistics manager level or higher;

- they had been in the company for 9.1 years, on average; and

- they had held their current position for an average of 5.6 years.

Following Armstrong and Overton (1977), non-response bias was evaluated by comparing answers from early and late respondents, but no indication of non-response bias was found.

On the basis of this second sample, again the full scale of five indicators was tested; first based on Cronbach alpha and EFA. The Cronbach alpha value is very good at 0.93 . The EFA showed that all items load on one factor, which explains 78.648 per cent of the variance. The second generation fit measures for the CFA $\left(\chi^{2}=18.440(\mathrm{df}=5\right.$; $p=0.002$ ); normed $\chi^{2}=3.688, \mathrm{CFI}=0.988, \mathrm{TLI}=0.976$; RMSEA $\left.=0.104\right)$ indicate a somewhat low fit. The problems again appear to be attributed to indicator 1 , whose error term here is strongly correlated to those of indicators 3 and 4. Eliminating indicator 1 from the measurement model, again, results in a single-factor four itemscale (see Table V) with much improved fit (Cronbach $\alpha=0.91, \chi^{2}=0.181(\mathrm{df}=2$; $p=0.913)$; normed $\chi^{2}=0.091, \mathrm{CFI}=1.000$, TLI $=1.007$; $\mathrm{RMSEA}=0.000$ ).

\begin{tabular}{lc}
\hline Industry & Percentage \\
\hline Automotive & \\
Chemicals and plastics & 4.8 \\
Consumer goods & 10.8 \\
Electronics and related instruments & 16.9 \\
Food and beverage & 8.0 \\
Healthcare & 17.7 \\
Industrial equipment & 8.8 \\
Retailing & 5.2 \\
Others & 9.6 \\
Annual revenue (in millions of US-dollar) & 15.3 \\
$<100$ & \\
100-249 & 6.5 \\
$250-499$ & 10.6 \\
$500-999$ & 11.8 \\
$\geq 1,000$ & 10.2 \\
No response & 58.9 \\
& 2.0
\end{tabular}

Note: $n=250$

\section{Scale for proactive improvement}

13 
IJLM
21,1

14

Table V.

Measurement scale results for the replication sample (USA)
Proactive improvement

Mean SD Item reliability

The LSP puts strong effort into continuously optimizing

logistics processes

The LSP continuously makes suggestions for improvements of activities, even those outside its direct responsibility

When the situation changes, the LSP by itself modifies the

logistics activities and processes, if this is useful and

necessary

The LSP shows initiative by approaching us with

suggestions for improvement

The LSP shows a high level of innovation

Notes: Cronbach $\alpha=0.91$, AVE $=0.74$, composite reliability $=0.92 ; n=250$
Eliminated

$\begin{array}{lll}4.53 & 1.44 \quad 0.83\end{array}$

$\begin{array}{lll}4.34 & 1.50 \quad 0.42\end{array}$

$\begin{array}{lll}4.62 & 1.52 & 0.90\end{array}$

$\begin{array}{lll}4.38 & 1.55 \quad 0.82\end{array}$

The findings of the replication sample reinforce those of the validation sample, including additional support for the decision to discard indicator 1 . The fact that the two national settings demonstrate such similar scale results provides promise for the validity of the proactive improvement construct.

\subsection{Scale differentiation}

Drawing upon Mentzer and Konrad (1991) and Stainer (1997), any change to a logistics system may be a value-providing improvement for the customer because it either increases the efficiency or effectiveness of the customer's logistics system. Although efficiency relates to the cost dimension and necessary inputs, effectiveness relates to output of the system and in this sense, to its performance. Therefore, to gain a more refined understanding, it seems plausible to further differentiate the general domain of proactive improvement into the two primary areas of cost and service performance.

LSPs can achieve a service advantage through the value provided to their customer while productivity advantage is reflected in the cost incurred to their customer, per Porter's (1985) differentiation strategy paradigm. Further, Christopher (2005) emphasizes that organizations may use logistics to gain competitive advantage both through "cost and service leadership". On the basis of these assertions, it is appropriate to distinguish proactive improvements made by an LSP within an ongoing relationship according to the two possible areas of effect: cost improvements and performance improvements. The former relates to cost reductions to the customer's logistics system in which the LSP's logistics services are embedded. The latter refers to improved performance of the customer's logistics system through enhancement of the services that are provided by the LSP. These aspects are vital for the efficiency (costs) and effectiveness (performance) of any outsourcing relationship.

A unique scale for each aspect of proactive improvement was devised to complement the general scale but also to prove the adaptability of the original scale to the distinct aspects of cost- and service-focused improvements. Such scales may be of particular interest in future studies. To address this objective, the general proactive improvement scale plus the eliminated indicator were refined to reflect the two specific domains of proactive improvement. As displayed in Table VI, the only difference is that the proactive cost improvement scale makes specific reference to improvements 
Item

Proactive cost improvement ${ }^{\text {a }}$

The LSP puts strong effort into continuously making logistics processes more cost-efficient

The LSP continuously makes suggestions for making activities more cost efficient, even those outside its direct responsibility

When the situation changes, the LSP by itself modifies the logistics activities and processes, if this is useful and necessary to reduce costs

The LSP shows initiative by approaching us with suggestions to reduce costs

The LSP shows a high level of innovation with respect to cost reductions

Proactive performance improvement ${ }^{\mathrm{b}}$

The LSP puts strong effort into continuously making logistics processes more effective

The LSP continuously makes suggestions for making activities more effective, even those outside its direct responsibility

When the situation changes, the LSP by itself modifies the logistics activities and processes, if this is useful and necessary to enhance the performance

The LSP shows initiative by approaching us with suggestions to enhance the performance

The LSP shows a high level of innovation with respect to performance improvements
Mean SD Item reliability

Eliminated

$\begin{array}{lll}3.39 & 1.61 & 0.71\end{array}$

$\begin{array}{lll}3.97 & 1.63 & 0.66\end{array}$

$\begin{array}{lll}3.67 & 1.72 & 0.84\end{array}$

$\begin{array}{lll}3.52 & 1.63 & 0.69\end{array}$

\section{Eliminated}

$\begin{array}{lll}3.23 & 1.59 & 0.67\end{array}$

$\begin{array}{lll}3.91 & 1.67 & 0.69\end{array}$

$\begin{array}{lll}3.75 & 1.63 & 0.82\end{array}$

$3.98 \quad 1.59 \quad 0.72$

Notes: ${ }^{\text {aCronbach }} \alpha=0.91, \mathrm{AVE}=0.73$, composite reliability $=0.91$; ${ }^{\mathrm{b}} \mathrm{Cronbach} \alpha=0.91$, AVE $=0.72$, composite reliability $=0.91 ; n=298$

Table VI.

Measurement scale results for the scale differentiation (Germany)

intended to increase cost efficiency and reduce costs, although the proactive performance improvement scale refers to improvements that increase effectiveness and enhance the performance of the customer's logistics system.

The initial setting (Germany) was used to validate the two specific proactive improvement scales. The data were again collected with a web-based survey consistent with the guidelines by Griffis et al. (2003) and incentives and two friendly reminder emails were used following Larson and Poist (2004) to increase the response rate.

The sample consisting of 1,784 potential respondents from German companies was drawn from the same company database as the original German sample. Although using the same selection criteria, this time a larger number of potential respondents were selected. The sample offers a good representation of the basic population of logistics executives in manufacturing and trading industries in Germany. All potential participants received a pre-notification e-mail outlining the goals of the study (Mehta and Sivadas, 1995) and a few days later a link to the web-based survey. The survey generated 298 completed questionnaires, which translates to a usable response rate of 16.7 per cent. When considering declining response rates over the last decade, this response rate can still be regarded as adequate (Cycyota and Harrison, 2006). The sample shows broad representation of all company sizes and across the manufacturing and trading industries (see Table VII). Due to their expertise and experience, primarily 
Industry

Automotive

Chemicals and healthcare

Consumer goods

$\begin{array}{lr}\text { Electronics and related instruments } & 13.7\end{array}$

Industrial equipment

Others

Annual revenue (in millions of euros)

$<100$

Table VII.

500-999

$\geq 1,000$

21.6
Sample descriptions for the scale differentiation (Germany)

Note: $n=298$

senior managers responsible for logistics were addressed and their competency assessed (Kumar et al., 1993). On average, the informants had been in their current position for eight years with no one holding their position for less than one year.

The extended scales with five indicators for each factor (the four established items plus the additional item that had been eliminated in the two previous phases) does not show satisfactory fit in the two-factor CFA (normed $\chi^{2}=7.707, \mathrm{CFI}=0.940$, TLI $=0.906$; RMSEA $=0.150$ ). The misfit is attributed to the previous eliminated indicator 1 (here, cost improvement item 1 and performance improvement item 1). Those two indicators are highly correlated and, thus, load on one common factor in the EFA. Further, the error terms of these two indicators are highly correlated to the error terms of the indicators 2 and 5 of the respective constructs. Consequently, eliminating indicator 1 from the measurement model improves the fit more than would the elimination of any other indicator.

The refined model with the indicators 2-5 for both constructs demonstrates an improved degree of fit. The EFA of all eight items shows that the indicators for each of the constructs load cleanly on two distinct factors (see Table VIII), demonstrating virtually no indication of cross-loading. Together, the two factors explain 82.37 per cent of the variance. These results provide a first indication of both convergent and discriminant validity.

\begin{tabular}{lcr}
\hline & Factor 1 & Factor 2 \\
\hline Proactive cost improvement 1 & 0.287 & 0.618 \\
Proactive cost improvement 2 & 0.130 & 0.776 \\
Proactive cost improvement 3 & 0.014 & 0.930 \\
Proactive cost improvement 4 & -0.102 & 1.016 \\
Proactive performance improvement 1 & 0.910 & -0.012 \\
Proactive performance improvement 2 & 0.814 & 0.083 \\
Proactive performance improvement 3 & 0.976 & -0.069 \\
Proactive performance improvement 4 & 0.816 & 0.128 \\
\end{tabular}

Table VIII.

EFA of differentiated scales 
Further, Cronbach alpha values of 0.912 and 0.910, respectively, provide strong support for convergence and measurement reliability for the scales. Additionally, the results from the two-factor CFA show satisfactory fit for the refined scales $\left(\chi^{2}=59.422\right.$ $(\mathrm{df}=15 ; \quad p<0.001) ; \quad$ normed $\quad \chi^{2}=3.961, \quad$ CFI $=0.980, \quad$ TLI $=0.963 ;$ RMSEA $=0.100)$. The AVE's for both scales exceed 0.7, the composite reliabilities 0.9. In all instances the item reliabilities exceed 0.65 (see Table VI). The non-standardized parameter estimates are provided in Table IX.

Discriminant validity was tested via the $\chi^{2}$ difference test proposed by Garver and Mentzer (1999). The two dimensions of proactive improvement are discriminant at $p<0.001$. Additionally, although the correlation of the two constructs is 0.89 , the confidence interval around this correlation never includes 1 , which provides strong indication for discriminant validity between the constructs (Anderson and Gerbing 1988; Smith and Barclay 1997; Chiou et al., 2002). Further, only very minor crossloadings among the items and the error terms of the proactive cost improvement scale and the proactive performance improvement scale, and vice versa, could be observed.

The findings of the differentiation sample further reinforce those of the two previous samples with respect to elimination of indicator 1 . The fact that even the differentiated scales demonstrate such similar results is a further indication of high validity of the proactive improvement construct.

\section{Discussion of findings}

As was indicated by the Langley (2008) study described in the beginning of this paper, continuous improvement activities by LSPs leave much to be desired. Although descriptive industry analyses underscore the importance of proactive improvement in outsourcing relationships, very little empirical work exists to assess the relative influence and merit of such tendencies/actions. Central to this premise is the development of a reliable scale for effectively measuring the construct of proactive improvement. The current research, thus, provides a good foundation for future research by developing and testing a measurement scale for this construct in three different forms - general, cost-focused, and service-focused improvement.

Furthermore, our results support the findings from the Langley (2008) study in that they show the proactive improvements as perceived by customers of LPSs to be rather low. The average is 3.64 regarding cost improvements and 3.72 regarding performance improvements (measured on a scale from a minimum of 1 to a maximum of 7 ). In the latest data from Germany (differentiation sample) only in 5.4 per cent of cases is

\begin{tabular}{|c|c|c|c|c|c|c|}
\hline & Estimate & $\mathrm{SE}$ & $t$-value & $p$ & Label & \\
\hline \multicolumn{7}{|c|}{ Cost improvement } \\
\hline Cost 5 & 1.000 & & & & & \\
\hline Cost 4 & 1.169 & 0.059 & 19.893 & 0.001 & par_1 & \\
\hline Cost 3 & 1.006 & 0.059 & 17.043 & 0.001 & par_2 & \\
\hline Cost 2 & 1.001 & 0.056 & 17.850 & 0.001 & par_3 & \\
\hline \multicolumn{7}{|c|}{ Performance improvement } \\
\hline Perf 4 & 1.102 & 0.054 & 20.280 & 0.001 & par 4 & Table IX \\
\hline Perf 3 & 1.039 & 0.058 & 18.001 & 0.001 & par 5 & Non-standardized \\
\hline Perf 2 & 0.968 & 0.056 & 17.409 & 0.001 & par_6 & parameter estimates \\
\hline
\end{tabular}

Scale for proactive improvement 
IJLM

21,1

18 proactive improvement considered to be excellent (where customers assign one of the top two scores of 6 or 7 ).

Our research employs a thorough multi-phase approach that utilizes three large samples from Germany and the USA. All three samples show consistent results toward establishing a measurement scale for proactive improvement. In all settings, the same indicator (Item 1) was eliminated. This is support for the proposed measurement scale as it appears to be robust against changes in the context. Thus, this scale should not only be useful for logistics research, but can most likely also be applied in other settings where ex post adaptation of products and especially services is a domain of interest.

On the basis of the newly established scale, the next areas of research should investigate the relevance of proactive improvement and its effect within outsourcing relationships. For the customer, proactive improvements will provide value as the services it outsources will usually require some degree of adaptation over time to remain optimal for the customer's logistics system for several reasons. Proactive improvement, however, also yields relationship value to the customer. Following Williamson (1991, 2008) and Skjoett-Larsen (2000), it is not possible to contractually specify all details of an outsourcing relationship ex ante. Therefore, the customer is uncertain about the LSP's future behavior and does not know whether the LSP will act in the customer's best interest or rather behave opportunistically when given the chance. Here, proactive improvement comes into play, which shows commitment on behalf of the LSP. In Williamson's terminology this is a "credible commitment" that reduces the uncertainty of the customer and adds to his relationship value by reducing risk and increasing the trustworthiness of the LSP.

Consequently, future research should attempt to measure the value enhancements provided to customers through proactive improvement and how this value is split up into relational and functional value. In this respect, it is noteworthy that ex post adaptation becomes more important in logistics outsourcing arrangements as they increase in complexity, scope and contract duration. At the same time, competencies of LSPs are growing while the customers - due to their increasing use of outsourcing may be reducing their in-house logistics competencies. This makes LSPs even more important in driving relationship-specific enhancements. Further, research should investigate what aspects and areas of proactive improvement are most important to customers and to what degree this may depend on the context of the outsourcing relationship.

For the LSP, proactive improvement should be relevant through the value it provides to the customer. This value, in turn, fosters customer loyalty as can be derived from SET (Thibaut and Kelley 1959; Lambe et al., 2001). To validate this conceptual assertion, future research should investigate how proactive improvement affects customer loyalty, but also how it is linked to profitability of the LSP.

A further aspect to be researched is how proactive improvement can be fostered and how corresponding efforts made by LSPs translate into effects that can be observed by their customers. In this respect, customers may question whether their selection and usage policy might affect the proactive improvement efforts of the LSPs they use. Further analyses of the data collected show that the volume of business dedicated to the LSP (measured as the share of total logistics costs) actually does not influence the LSP's proactive improvement behaviors neither with respect to cost nor with respect to performance improvements. This shows, on the one hand, that LSPs that have captured a large outsourcing share do not tend to become more complacent. On the 
other hand, LSPs do not seem to be able to realize economies of scale with respect to proactive improvement. Such scale advantages could be gained by dedicating focused management resources, which usually is not possible for small outsourcing projects. Also, the relationship age does not significantly affect the level of proactive improvement. This suggests that LSPs do not get inattentive over the course of time. Yet, LSPs also do not seem to utilize the improved understanding of the customer that develops over time to enhance proactive improvement. For the customer, this means that dedicating significant volumes of business to one LSP and long-lasting relationships, in general, does not lead to a reduction in improvement efforts by the LSP.

Proactive improvement seems based on the willingness, but also the empowerment/ incentives of the personnel in charge. Here, Deepen et al. (2008) identifies that proactive improvements are driven by cooperation and increase as the relationship becomes closer. Still, future research should investigate, more specifically, which elements of interaction are vital for proactive improvements. Moreover, theory and practice would benefit from knowing how LSPs can best facilitate and manage their own proactive improvement efforts and how customers can enable and encourage proactive improvements. One possible approach to the latter may lie in the very structure of the underlying remuneration. By including variable outcome-based compensation components into contracts that determine a certain proportion of their payment, LSPs might be more directly encouraged to increase their improvement efforts.

\section{References}

Anderson, J.C. and Gerbing, D.W. (1988), "Structural equation modeling in practice: a review of the two-step approach”, Psychological Bulletin, Vol. 103 No. 3, pp. 411-23.

Armstrong, J.S. and Overton, T.S. (1977), "Estimating non-response bias in mail surveys", Journal of Marketing Research, Vol. 14 No. 3, pp. 396-402.

Beverland, M. and Lockshin, L. (2003), "A longitudinal study of customers' desired value change in business-to-business markets", Industrial Marketing Management, Vol. 32 No. 8 , pp. 653-67.

Beverland, M., Farrelly, F. and Woodhatch, Z. (2007), "Exploring the dimensions of proactivity within advertising agency-client relationships", Journal of Advertising, Vol. 36 No. 4, pp. 49-60.

Bhatnagar, R. and Viswanathan, S. (2000), "Alliances between manufacturing firms and global logistics service providers", International Iournal of Phvsical Distribution \& Logistics Management, Vol. 30 No. 1, pp. 13-34.

Chiou, J.-S., Droge, C. and Hanvanich, S. (2002), "Does customer knowledge affect how loyalty is formed?", Iournal of Service Research, Vol. 5 No. 2, pp. 113-24.

Christopher, M. (2005), Logistics and Supply Chain Management, 3rd ed., FT Prentice Hall, Harlow.

Cycyota, C.S. and Harrison, D.A. (2006), "What (not) to expect when surveying executives: a metaanalysis of top manager response rates and techniques over time", Organizational Research Methods, Vol. 9 No. 2, pp. 133-60.

Deepen, J.M., Goldsby, T.J., Knemeyer, A.M. and Wallenburg, C.M. (2008), “Beyond expectations: an examination of logistics outsourcing goal achievement and goal exceedance", Lournal of Business Logistics, Vol. 29 No. 2, pp. 75-105.

Engelbrecht, C. (2004), Logistikoptimierung durch Outsourcing - Erfolgswirkung und Erfolgsfaktoren (Logistics Optimization through Outsourcing - Performance Implications and Key Success Factors), Gabler, Wiesbaden.

Scale for proactive improvement 
IJLM

21,1

Flint, D.J., Woodruff, R.B. and Gardial, S.F. (2002), "Exploring the phenomenon of customers' desired value change in a business-to-business context", Journal of Marketing, Vol. 66 No. 4, pp. 102-17.

Flint, D.J., Larsson, E., Gammelgaard, B. and Mentzer, J.T. (2005), "Logistics innovation: a customer value-oriented social process", Journal of Business Logistics, Vol. 26 No. 1, pp. 113-47.

Garver, M.S. and Mentzer, J.T. (1999), "Logistics research methods: employing structural equation modeling to test for construct validity”, Journal of Business Logistics, Vol. 20 No. 1, pp. 33-57.

Griffis, S.E., Goldsby, T.J. and Cooper, M. (2003), "Web-based and mail surveys: a comparison of response, data and cost”, Lournal of Business Logistics, Vol. 24 No. 2, pp. 237-58.

Keller, S.B., Savitske, K., Stank, T.P., Lynch, D.F. and Ellinger, A.E. (2002), "A summary of multiitem scales used in logistics research", Journal of Business Logistics, Vol. 23, pp. 83-281.

Kumar, N., Stern, L.W. and Anderson, J.C. (1993), "Conducting interorganizational research using key informants”, Academv of Management Journal, Vol. 36 No. 6, pp. 1633-51.

Kydd, A. (2000), "Trust, reassurance and cooperation", International Organization, Vol. 54 No. 2, pp. 325-57.

Lambe, C.J., Wittmann, C.M. and Spekman, R.E. (2001), "Social exchange theory and research on business-to-business relational exchange", Journal of Business-to-Business Marketing, Vol. 8 No. 3, pp. 1-36.

Langley, J. (2008), “Third party logistics: results and findings of the 13th annual study”, available at: www.scl.gatech.edu/research/supply-chain/3pl.php

Larson, P.D. and Poist, R.F. (2004), "Improving response rates to mail surveys: a research note", Transportation Journal, Vol. 43 No. 4, pp. 67-74.

Lemon, K.N., White, T.B. and Winer, R.S. (2002), "Dynamic customer relationship management: incorporating future considerations into the service retention decision", Iournal of Marketing, Vol. 66, pp. 1-14.

Mehta, R. and Sivadas, E. (1995), "Comparing response rates and response content in mail versus electronic mail surveys", Journal of the Market Research Societv, Vol. 37 No. 4, pp. 429-39.

Mentzer, J.T. and Konrad, B.P. (1991), "An efficiency/effectiveness approach to logistics performance analysis", Journal of Business Logistics, Vol. 12 No. 1, pp. 33-61.

Murphy, P.R. and Wood, D.F. (2004), Contemporary Logistics, 8th ed., Pearson Prentice Hall, Upper Saddle River, NJ.

Porter, M.E. (1985), Competitive Advantage, The Free Press, New York, NY.

Rindfleisch, A. and Heide, J.B. (1997), "Transaction cost analysis: past, present, and future applications", Journal of Marketing, Vol. 61 No. 4, pp. 30-54.

Rogers, E. (1995), Diffusion of Innovations, 4th ed., The Free Press, New York, NY.

Skjoett-Larsen, T. (2000), "Third party logistics - from an interorganizational point of view", International Iournal of Phvsical Distribution \& Logistics Management, Vol. 30 No. 2, pp. 112-27.

Smith, J.B. and Barclay, D.W. (1997), "The effects of organizational differences and trust on the effectiveness of selling partner relationships", Journal of Marketing, Vol. 61 No. 1, pp. 3-21.

Stainer, A. (1997), "Logistics - a productivity and performance perspective", Supply Chain Management: An International Iournal, Vol. 2 No. 2, pp. 53-62.

Thibaut, J.W. and Kelley, H.H. (1959), The Social Psychology of Groups, Wiley, New York, NY, London, and Sydney.

Ulaga, W. and Eggert, A. (2006), "Relationship value and relationship quality", European Iournal of Marketing, Vol. 40 Nos 3/4, pp. 311-27. 
Wallenburg, C.M. (2009), "Innovation in logistics outsourcing relationships: proactive improvement by logistics service providers as a driver of customer loyalty”, Iournal of Supply Chain Management, Vol. 45 No. 2, pp. 75-93.

Williamson, O.E. (1985), The Economic Institutions of Capitalism: Firms, Markets, Relational Contracting, The Free Press, New York, NY.

Williamson, O.E. (1991), "Comparative economic organization: the analysis of discrete structural alternatives”, Administrative Science Quarterly, Vol. 36 No. 2, pp. 269-96.

Williamson, O.E. (1993), "Calculativeness, trust, and economic organization", Journal of Law \& Economics, Vol. 36 No. 1, pp. 453-86.

Williamson, O.E. (2005), "Why law, economics, and organization?", Annual Review of Law and Social Science, Vol. 1, pp. 369-96.

Williamson, O.E. (2008), "Outsourcing: transaction cost economics and supply chain management”, Journal of Supplv Chain Management, Vol. 44 No. 2, pp. 5-16.

\section{Further reading}

Woodruff, R.B. and Flint, D.J. (2003), "Research on business-to- business customer value and satisfaction", Advances in Business Marketing and Purchasing, Vol. 12, pp. 515-47.

\section{Corresponding author}

A. Michael Knemeyer can be contacted at: knemeyer.4@osu.edu

To purchase reprints of this article please e-mail: reprints@emeraldinsight.com Or visit our web site for further details: www.emeraldinsight.com/reprints 


\section{This article has been cited by:}

1. Gino Marchet, Marco Melacini, Chiara Sassi, Elena Tappia. 2017. Assessing efficiency and innovation in the 3PL industry: an empirical analysis. International Journal of Logistics Research and Applications 20:1, 53-72. [CrossRef]

2. Adriana Rossiter Hofer, A. Michael Knemeyer, Paul R. Murphy. 2015. Achieving and Exceeding Logistics Outsourcing Expectations in Brazil:. Transportation Journal 54:3, 339-367. [CrossRef]

3. Nor Aida Abdul Rahman, T.C. Melewar, Amir M. Sharif. 2014. The establishment of industrial branding through dyadic logistics partnership success (LPS): The case of the Malaysian automotive and logistics industry. Industrial Marketing Management 43:1, 67-76. [CrossRef]

4. Adriana Rossiter Hofer, A. Michael Knemeyer, Paul R. Murphy. 2012. The Roles of Procedural and Distributive Justice in Logistics Outsourcing Relationships. Journal of Business Logistics 33:3, 196-209. [CrossRef] 